\title{
Neuropsychiatric complications of commonly used palliative care drugs
}

\author{
N Jackson, J Doherty, S Coulter
}

Northern Ireland Hospice Care, Belfast, Northern Ireland

Correspondence to: Dr Neil Jackson, Northern Ireland Hospice Care, 74

Somerton Road, Belfast, BT15

3LH, Northern Ireland;

neil.jackson@nihospicecare.com

Received 30 May 2007 Accepted 15 January 2008

\section{ABSTRACT}

For those facing progressive life limiting disease, symptoms across a range of systems can be problematic. Clinicians may find themselves prescribing from several classes of drugs to alleviate distressing problems and to maximise quality of life for patients. Many drugs used for symptom control in palliative care give rise to neuropsychiatric side effects as they affect the central nervous system either directly or indirectly. The common unwanted effects of these drugs are well known, but there are some important neuropsychiatric effects that physicians are less aware of. If unrecognised, these effects can generate considerable distress and unnecessary harm to patients. We aim to highlight some of the adverse neuropsychiatric effects which occur with commonly used drugs in palliative care. Antiemetics such as metoclopramide and haloperidol can cause significant levels of neuropsychiatric toxicity, as can opiates, antidepressants, anxiolytics and antipsychotics. The syndromes or entities that will be considered are delirium, drug induced parkinsonism, akathisia, serotonin syndrome and neuroleptic malignant syndrome. The intention is to alert clinicians to the iatrogenic complications which may ensue on prescribing drugs commonly used in the palliative care setting.

The emphasis of palliative medicine is to optimise symptom control and quality of life for patients who are living with terminal disease. Any drug interventions must consider the balance of risks and benefits to ensure that patients do not experience any added distress. Many drugs used for symptom control in palliative care exert unwanted effects on the central nervous system. Some of these drugs show adverse neuropsychiatric or other toxic effects when used alone, in combination with other drugs, when given in high doses or when given over a prolonged period of time. Some of these toxicities are common and some less so, but they are all significant and potentially very harmful, and can be fatal. Clinicians may not be aware of the less common conditions such as akathisia, serotonin syndrome and neuroleptic malignant syndrome, and so symptoms may wrongly be attributed to a patient's condition, managed incorrectly and thus exacerbate the distress experienced. In raising awareness of these pitfalls, we seek to aid the detection and initiation of appropriate management for these conditions, in the pursuit of excellent, holistic and informed end of life care.

\section{DELIRIUM}

Delirium is a clinical syndrome which is diagnosed when there is a disturbance in consciousness and attention, with a change in cognition or perception. It usually develops over a period of hours to days, follows a fluctuating course and has evidence of an organic aetiology. ${ }^{12}$ It is frequently not recognised or misdiagnosed and is often poorly treated. ${ }^{3}$

Delirium is the most common clinical neuropsychiatric condition, occurring in $26-44 \%$ of admissions to hospitals or specialist palliative care units. ${ }^{2}$ Prevalence of up to $88 \%$ before death has been reported in specialist inpatient units, and it may be reversible in approximately $50 \%$ of episodes. ${ }^{4}$ It is estimated that medications alone may account for $12-39 \%$ of all cases of delirium. ${ }^{56}$ Drugs that cause delirium include opioids, antisecretory medication, anxiolytics, antipsychotics, antidepressant drugs, steroids and non-steroidal anti-inflammatory agents (NSAIDs) (table 1). ${ }^{7}$

The aetiology, diagnostic criteria, and management of delirium are covered in another paper in this series. ${ }^{1}$

\section{DRUG INDUCED PARKINSONISM}

Drug induced parkinsonism (DIP), sometimes also referred to as pseudo-parkinsonism, is the second most common cause of akinetic rigid syndrome in the western world. Its prevalence is increasing due to an ageing population and the rise of polypharmacotherapy. ${ }^{11}$ The syndrome has also been named neuroleptic-induced parkinsonism and antipsychotic-induced parkinsonism..$^{12}$

\section{Incidence}

Parkinsonism has a prevalence in the general population of around $7 \%$ in those over 50 years old. ${ }^{14}{ }^{15}$ DIP has a population prevalence of $2.7 \% .{ }^{15}$ In those over 60 years taking neuroleptics for psychiatric illness, prevalence of antipsychotic induced parkinsonism has been reported as exceeding $50 \%{ }^{13}$ Individual susceptibility to neuroleptics varies and the incidence of the syndrome increases with age. Antipsychotic dose and potency, a previous history of extra pyramidal signs and a previous history of dementia are the major risk factors for developing DIP. ${ }^{13}$ Most cases of DIP occur within the first 2-3 months of drug initiation. ${ }^{13}$ Although originally recorded as a side effect of neuroleptics, DIP has now been described with a wide range of compounds including antiemetics, antidepressants, calcium channel antagonists, antiarrhythmics, antiepileptics and cholinomimetics. $^{11} 1617$

\section{Pathophysiology}

Positron emission tomography (PET) studies have shown that $80 \%$ or more cerebral D2 receptor 
Table 1 Delirium inducing drugs commonly used in palliative medicine $^{6-10}$

\begin{tabular}{|c|c|}
\hline Opioids & $\begin{array}{l}\text { For example, morphine, fentanyl, oxycodone. The risk of } \\
\text { delirium associated with opioids is dose related }\end{array}$ \\
\hline Anti-secretory medication & $\begin{array}{l}\text { For example, hyoscine hydrobromide (anticholinergic } \\
\text { effect) }\end{array}$ \\
\hline Anxiolytics & For example, midazolam, diazepam, lorazepam \\
\hline \multirow[t]{2}{*}{ Antipsychotics } & $\begin{array}{l}\text { Antipsychotics, especially those with an anticholinergic } \\
\text { effect, can induce delirium, and all traditional } \\
\text { antipsychotic drugs confer an increased risk }\end{array}$ \\
\hline & $\begin{array}{l}\text { Levomepromazine (methotrimeprazine/nozinan), a } \\
\text { frequently used anti-emetic, has considerable } \\
\text { anticholinergic properties and therefore presents a high } \\
\text { risk of inducing delirium }\end{array}$ \\
\hline Antidepressant drugs & $\begin{array}{l}\text { All tricyclic antidepressant drugs exert an } \\
\text { anticholinergic effect, with amitryptiline having the } \\
\text { strongest and nortriptyline the weakest. The tricyclic } \\
\text { antidepressants constitute a high risk group of drugs }\end{array}$ \\
\hline Anticonvulsants & $\begin{array}{l}\text { All anticonvulsants have been reported to induce } \\
\text { delirium, although the mechanisms are uncertain with } \\
\text { probable differences between different drugs }\end{array}$ \\
\hline Steroids & $\begin{array}{l}\text { Adverse central nervous system (CNS) effects } \\
\text { associated with corticosteroid treatment include } \\
\text { delirium and chronic cognitive impairment, the risk } \\
\text { being dose related }\end{array}$ \\
\hline NSAIDs & $\begin{array}{l}\text { All non-steroidal anti-inflammatory drugs (NSAIDs) have } \\
\text { been reported to induce delirium }\end{array}$ \\
\hline Gastrointestinal agents & Antispasmodics and $\mathrm{H}_{2}$ blockers \\
\hline Antibiotics & Fluoroqinolones-for example, ciprofloxacin \\
\hline Antihistamines & $\begin{array}{l}\text { First generation-for example, diphenhydramine and } \\
\text { chlorpheniramine }\end{array}$ \\
\hline
\end{tabular}

occupancy is consistent with the appearance of DIP. Occupancy of $40-70 \%$ of D2 receptors induces no DIP. ${ }^{16}$ Conventional neuroleptics such as haloperidol tend to induce high $\mathrm{D} 2$ receptor occupancy, whereas atypical neuroleptics cause lower occupancy rates and hence less DIP.

\section{Clinical features}

Bradykinesia is the earliest and most common sign, with muscular rigidity and disturbances of posture and gait developing later. Tremor is less apparent than in Parkinson's disease. ${ }^{16}$ Hypersalivation can occur. The development of these features is broadly dose dependent. Although traditionally considered reversible, DIP may persist after drug withdrawal. ${ }^{18}$ At least $10 \%$ of patients with DIP developed persistent and progressive parkinsonism even when the causative drug had been discontinued. ${ }^{11}$

Special precautions are needed in the elderly, in patients treated with multiple potentially causative drugs for prolonged periods of time, and in those with familial parkinsonism or tremor. ${ }^{11}$

\section{Management}

Monitoring patients in the early weeks of treatment will help early detection of DIP. Initial management of this disorder involves withdrawal of the causative drug(s). If discontinuation is not possible then a switch from a conventional to an atypical neuroleptic should be considered. If the drug(s) cannot be altered then it is advisable to add anticholinergic medication such as procyclidine. In the elderly, adding amantadine is recommended to prevent anticholinergic side effects. ${ }^{16}$

\section{AKATHISIA}

Akathisia is an idiopathic condition characterised by a state of restlessness and motor agitation most frequently observed in

\section{Box 1: Non-neuroleptic drugs which cause akathisia ${ }^{23}$}

- Antiemetics: metoclopramide, prochlorperazine, [domperidone]

- Antidepressants: tricyclics, selective serotonin reuptake inhibitors (fluoxetine, paroxetine, sertraline), venlafaxine, [nefazodone]

- Calcium channel blockers: cinnarizine, flunarizine (also $\mathrm{H}_{1}$ antagonists), [diltiazem]

- Others: methyldopa, levodopa, and dopamine antagonists, [lithium carbonate], buspirone, [anticonvulsants], [pethidine], [interferon $\alpha$ ], [sumatriptan]

[ ] = anecdotal or not well established evidence

association with antipsychotic drugs. ${ }^{19-21}$ It has also been observed with a number of other drugs, including antidepressants and metoclopramide. ${ }^{22-24}$ It was first described in 1909 by Hasvonec to describe restless patients suffering from hysteria and neurasthenia and is derived from the Greek term meaning "not to sit". ${ }^{22}{ }^{25}$ Box 1 provides a list of non-neuroleptic drugs which may cause akathisia. Neuroleptics and some of the other drugs listed in box 1 are commonly used in the palliative care setting and it is therefore important that the presence of akathisia is recognised to avoid unnecessary patient distress.

If the symptoms of akathisia are misdiagnosed as an exacerbation of agitation or psychosis, this might lead to an increase in antipsychotic medication which would serve to aggravate the problem further. ${ }^{21} 232627$ Most research into this condition has been undertaken in the psychiatry setting; however, the recognition and treatment of akathisia is important in the palliative care population. ${ }^{25}$

\section{Incidence}

The reported incidence rates for neuroleptic induced akathisia exhibit wide variation and this may reflect the lack of commonly accepted diagnostic criteria. ${ }^{26}$ Prevalence is likely to be between $20-75 \%{ }^{22} 2829$

\section{Pathophysiology}

The underlying cause of akathisia is not well understood but may be related to dopamine blockade in the mesocortical dopamine pathway. ${ }^{20-22}{ }^{30}$ Involvement of central serotonergic and adrenergic neurotransmitter systems has also been postulated. ${ }^{31}$ Risk factors for developing neuroleptic induced akathisia are not completely understood. Both drug dose and rate of increment of dose are important risk factors. ${ }^{24} 283233$ Exposure to pharmacologically similar drugs, such as haloperidol, prochlorperazine and promethazine has been shown to confer an increased risk. Risk is also increased in patients who are concurrently taking morphine or sodium valproate. ${ }^{21} 29$

\section{Clinical features}

There is a considerable amount of debate in the literature regarding the exact definition of akathisia. Most authors would agree that akathisia is part of the spectrum of extrapyramidal side effects. ${ }^{20}$ Patients experience an inability to relax and are unable to tolerate being still. There is a subjective feeling of restlessness and objective motor agitation. ${ }^{21}{ }^{26}$ The symptoms fall into a spectrum which in its mild form is characterised by incessant shuffling or tapping of the feet while seated and continuous shifting of weight and rocking of the trunk when 
standing. In the more severe manifestations, akathisia can be exhibited as an inability to sit, stand or lie still, or as pacing or incessant running. ${ }^{1922}{ }^{26}$ The movement disorder is greatest in or restricted to the lower limbs. ${ }^{34}$ The movements tend to be bilateral and symmetrical; however, there is no single motor feature pathognomic for the condition. ${ }^{20}{ }^{35}$ Akathisia can therefore be considered to be a combination of restlessness, patient distress, tension and discomfort.

Akathisia usually has an onset of days to weeks after commencement of a causative drug. ${ }^{24}$ It is imperative that the possibility of akathisia is considered when using these drugs so that treatment can be instigated without delay. ${ }^{34}$ The Diagnostic and statistical manual, 4th revision (DSM-IV) research criteria in box 2 for neuroleptic associated akathisia can also be applied to akathisia caused by other drugs and is useful in diagnosis.

The Barnes akathisia rating scale (BARS) is a tool used to detect and monitor akathisia in patients treated with psychiatric medication. It measures both the motor features and the discomfort the patient experiences and is considered to be both reliable and valid. ${ }^{36}$

\section{Management}

The best possible treatment is avoidance of potentially causative agents. In situations where this is not possible, it has been recommended that these drugs should be judicially used and carefully monitored. ${ }^{21}$ The newer atypical antipsychotic drugs are felt to be less likely to produce acute akathisia and should therefore be used preferentially. ${ }^{22} 3238$

The clinician should have a high index of suspicion and if akathisia is thought to be present then the presumed causative drug should be discontinued or reduced. ${ }^{23}{ }^{29}$ Symptoms should resolve within days of stopping the drug. If the patient is very symptomatic, there are a number of other drugs which can be used to counteract the symptoms. $\beta$-blockers are considered to be the most useful drugs in treatment. ${ }^{23}$ Their mechanism of

\section{Box 2: DSM-IV-TR research criteria for neuroleptic}

\section{induced acute akathisia}

A. The development of subjective complaints of restlessness after exposure to a neuroleptic medication.

B. At least one of the following is observed:

- fidgety movements or swinging of the legs

- rocking from foot to foot while standing

- pacing to relieve restlessness

- inability to sit or stand still for at least several minutes

C. The onset of symptoms in criteria A and B occurs within 4 weeks of initiating or increasing the dose of the neuroleptic, or of reducing the medication used to treat (or prevent) acute extrapyramidal symptoms-for example, anticholinergics.

D. The symptoms in criterion A are not better accounted for by a mental disorder (for example, schizophrenia, substance withdrawal, or agitation from a major depressive or manic episode). Evidence that symptoms may be better accounted for by a mental disorder include the following: the onset of symptoms preceding the exposure to the neuroleptic, the absence of increasing restlessness with increasing doses, and the absence of relief with pharmacological intervention.

E. The symptoms in criterion A are not due to a non-neuroleptic substance or to a neurological or other general medical condition. ${ }^{37}$ action is thought to be adrenergic antagonism, which is beneficial because the adrenergic system is thought to exhibit overactivity as a result of dopamine blockade in this condition. ${ }^{22}$ Other drugs which have been used in treatment are benzodiazepines, cyproheptadine, and mianserin. ${ }^{19} 222439$

\section{SEROTONIN SYNDROME}

Serotonin syndrome, also referred to as serotonin toxicity, is a medication induced disorder which is the result of excessive serotonergic activity, culminating in a hyperthermic toxidrome. ${ }^{40-42}$ Features of serotonin syndrome range from those that are barely detectable to those which threaten life. Adding to this diagnostic difficulty, there is evidence that $85 \%$ of physicians are not aware of serotonin syndrome as a diagnostic entity. ${ }^{43}$ It is of relevance to patients at the end of life, as medications commonly used to control symptoms, including some opiate analgesics, have been implicated in its pathogenesis. ${ }^{44}$ In addition, early features of serotonin syndrome may be wrongly attributed to other causes and inadvertently treated with medications likely to exacerbate the patient's condition. ${ }^{45}$

\section{Incidence}

A rise in the witnessed incidence of serotonin syndrome is felt to be the result of increased prescribing of serotonergic drugs such as selective serotonin reuptake inhibitors (SSRIs). ${ }^{46}$ The true incidence of serotonin syndrome is unknown with reports consisting of case studies or post-marketing surveillance data from serotonergic drugs. ${ }^{47} 48$

\section{Clinical features}

Serotonin syndrome is considered a continuum of symptoms progressing from mild side effects to toxicity. ${ }^{41}$ It has been described as a clinical triad of neuro-excitatory features including mental status changes, autonomic hyperactivity and neuromuscular abnormalities. ${ }^{47} 49$ Three levels of severity of symptoms and signs have been described:

1. Mild state of serotonin related symptoms

2. Serotonin syndrome

3. Serotonin toxicity

In the presence of features suggestive of serotonin syndrome, the diagnosis can only be made when a patient has a history of serotonergic drug use. Differential diagnoses include neuroleptic malignant syndrome (NMS) and anticholinergic syndrome. ${ }^{42} 50$ Diagnosis has been historically guided by Sternbach's criteria which have been revised by Radomski in 2000 (box 3). ${ }^{51}{ }^{52}$

\section{Box 3: Sternbach's criteria}

Mental (cognitive and behavioural) status changes

- major symptoms: confusion, elevated mood, coma

- minor symptoms: agitation, nervous and insomnia

- Autonomic symptoms

- major symptoms: fever, hyperhidrosis

- minor symptoms: tachycardia, tachypnoea, dyspnoea, diarrhoea, hypotension, hypertension

- Neurological symptoms

- major symptoms: myoclonus, tremors, chills, rigidity, hyperreflexia

- minor symptoms: impaired coordination, mydriasis, akathisia 
The onset of serotonin syndrome is usually rapid, often taking place within hours of serotonergic medication ingestion. ${ }^{40} 53$ Initially the patient is alert with tremor and hyperreflexia. Mental status changes are present in $40 \%$ of recorded cases. ${ }^{40} 424754$ Neuromuscular signs are initially greater in the limbs. Autonomic features then follow but do not normally cause a management problem. Rigidity and temperature of over $38^{\circ} \mathrm{C}$ indicate life threatening toxicity. ${ }^{49}$

\section{Pathogenesis}

Drugs that elevate brain and spinal cord serotonin levels are capable of causing serotonin syndrome. Overdoses of serotonin reuptake inhibitors frequently produce pronounced serotonergic side effects and in $15 \%$ of cases moderate serotonin syndrome. ${ }^{49}$ There is clear evidence supporting a dose-effect relationship. ${ }^{55}$ Combinations of serotonergic drugs acting by different mechanisms are capable of producing life threatening serotonin syndrome. $^{49}$

The increase in SSRI prescribing seen in recent years is also evident in palliative care. This probably reflects an intention to avoid side effects posed by older antidepressants such as tricyclics. This trend, however, appears to correlate with an increasing incidence of serotonin syndrome. ${ }^{46}$ Patients with palliative care needs may already have elevated serotonin levels ${ }^{45}$ as endothelial damage resulting from severe illness can lead to reduced serotonin breakdown by monoamine oxidase activity.

\section{Drug causes}

Some opiate analgesics cause serotonin reuptake inhibition. In particular, pethidine, tramadol, fentanyl and dextromethorphan, when co-prescribed with monoamine oxidase inhibitors (MAOIs), have been implicated in fatalities from serotonin syndrome. ${ }^{404144}$ Morphine, codeine, oxycodone and buprenorphine by comparison have been shown not to inhibit serotonin reuptake and therefore are not implicated in serotonin syndrome. $^{49}$

Tricyclic antidepressants (TCAs) are used commonly for the treatment of neuropathic pain in a palliative setting. There is uncertainty as to which TCAs cause clinically significant rises in serotonin levels. Clomipramine exerts a notable serotonergic effect whereas amitriptyline does not. ${ }^{56} 5 \mathrm{HT}_{3}$ antagonists such as ondansetron may have a role in the development of serotonin syndrome, but this is still uncertain. ${ }^{57}$

Metoclopramide has been shown to cause serotonin syndrome when prescribed alongside SSRIs. ${ }^{58}$ Cyclizine and haloperidol have been implicated in mild serotonin syndrome, but their ability to cause significant toxicity is uncertain. Atypical antipsychotics, including risperidone, can result in significant serotonin syndrome, particularly when used in combination with SSRIs. ${ }^{59}$

\section{Treatment}

If serotonin syndrome is suspected, serotonergic drugs should be discontinued and no other precipitants administered. ${ }^{48}{ }^{50}$ Rapid resolution of features, usually within $24 \mathrm{~h}$, is seen in many cases upon cessation of the causative agent and supportive care. ${ }^{40} 42$ Some patients may have features persisting beyond $24 \mathrm{~h}$, symptom duration being influenced by the half life of the causative drug. ${ }^{50}$

In addition to supportive care there may be a role for pharmacological therapy in the treatment of serotonin syndrome. ${ }^{53}$ The intensity of intervention depends on the severity of toxicity. For mild cases, supportive management may include intravenous fluids and the administration of benzodiazepines. Some authors claim the control of agitation (for all levels of severity) by benzodiazepines is essential in the management of serotonin toxicity. ${ }^{47}$ Serotonin receptor antagonists may be administered. The effective use of cyproheptadine in the management of serotonin syndrome has been reported, although further evaluation is needed. Chlorpromazine has been used in patients with severe toxicity. ${ }^{55}$ Severe serotonin syndrome may be life threatening, particularly if MAOIs or SSRIs are co-ingested, and as such, early hospitalisation is recommended. ${ }^{49}$ In cases of severe toxicity, external cooling, muscular paralysis with neuromuscular blocking agents, mechanical ventilation and intravenous sedation in an intensive care unit are indicated. ${ }^{46}$

\section{NEUROLEPTIC MALIGNANT SYNDROME}

Neuroleptic malignant syndrome (NMS) is a rare but potentially lethal adverse reaction arising from the use of medications that involve the central dopaminergic system ${ }^{60}$ such as phenothiazines, butyrophenones and the more recent atypical agents. ${ }^{61-63}$

\section{Incidence and cause}

Several prospective studies from psychiatric settings have reported a prevalence of NMS ranging from $0.07-2.2 \%$ of patients receiving neuroleptics. ${ }^{64}$ It has been reported most commonly with haloperidol and depot agents used in psychiatry. It has also been reported with lithium, carbamazepine, desipramine, dothiepin and other neuroleptics. ${ }^{65} 66$

In the context of palliative care, NMS has been reported with use of metoclopramide and its withdrawal, ${ }^{61}$ 67-69 with levomepromazine, paroxetine and with the abrupt withdrawal of anticholinergic drugs. ${ }^{70-73}$

\section{Key references}

\section{Delirium}

- Del Fabbro E, Dalal S, Bruera E. Symptom control in palliative care-part III: dyspnea and delirium. J Palliat Med 2006;9:42236.

\section{Drug induced parkinsonism}

- Caligiuri MR, Jeste DV, Lacro JP. Antipsychotic-induced movement disorders in the elderly: epidemiology and treatment recommendations. Drugs Aging 2000;17:363-84.

\section{Akathisia}

- White $\mathrm{C}$, Jackson N. Acute akathisia in palliative care. Eur J Palliat Care 2005;12:5-7.

\section{Serotonin syndrome}

- Anderson T, Watson MS, Marr K. Serotonin syndrome: a hidden danger in palliative care. Eur J Palliat Care 2005;12:97100.

\section{Neuroleptic malignant syndrome}

- Kawanishi C, Onishi H, Kato D, et al. Neuroleptic malignant syndrome in cancer treatment. Palliat Support Care 2005;3:51-3. 


\section{Clinical features}

NMS is characterised by altered levels of consciousness, extrapyramidal effects (rigidity and akinesia), autonomic instability, hyperthermia, sweating and tremors or rigors. ${ }^{7-76}$ Muscle rigidity is the cardinal feature of NMS and is often associated with myonecrosis, myoglobinuria, and elevated serum creatinine phosphokinase (CPK) levels. ${ }^{77}$ Rigidity may be accompanied by tremor, oro-bucco-lingual dyskinesias and sometimes by dysphagia and dysarthria. Leucocytosis is frequently a feature. The symptoms and signs can occur very rapidly or over several days after commencement of a neuroleptic. Siallorrhoea, tachycardia, hyperventilation and labile blood pressure can also occur. ${ }^{78}$ The associated cerebral disturbance can present as confusion, delirium, stupor or coma. ${ }^{64} 79$

With altered levels of consciousness, dehydration is common. This, combined with rhabdomyolysis, can lead to acute renal failure, one of the more serious complication of NMS. ${ }^{74}$ Death has been reported to occur in $20-40 \%$ of cases. ${ }^{75} 8081$

\section{Management}

The following treatment algorithm has been suggested for $\mathrm{NMS}^{82}$ :

1. An immediate withdrawal of all neuroleptic medication as soon as the condition is suspected.

2. Evaluate the patient's fluid balance and hydrate accordingly.

3. If signs persist or worsen after the previous two steps, consider adding a minor tranquilliser such as lorazepam or diazepam.

4. If signs persist or worsen after step 3 consider adding bromocriptine or dantrolene. Dantrolene has been suggested where muscle tone is prominent; bromocriptine is suggested for cases with prominent mental status changes.

Neuroleptics should be used with caution in a patient with a previous history of NMS. Prevalence of recurrence of NMS with re-introduction of neuroleptic has been reported as $25-75 \%$.

\section{CONCLUSION}

Drugs commonly used for symptom control in palliative care can give rise to a wide range of neuropsychiatric phenomena. Delirium is frequently seen, akathisia and drug induced parkinsonism are less common, and serotonin syndrome and neuroleptic malignant syndrome are rare but can be fatal when missed. This article aims to raise awareness of drug related neuropsychiatric complications, to aid their detection and appropriate management, and thus improve symptom control at the end of life.

\section{MULTIPLE CHOICE QUESTIONS (TRUE (T)/FALSE (F); ANSWERS AFTER THE REFERENCES)}

\section{Akathisia:}

(A) Akathisia is a condition characterised by objective motor agitation and subjective inner restlessness

(B) Akathisia is most commonly observed in patients taking neuroleptic drugs but can also occur with other nonneuroleptic medications such as prochlorperazine

(C) Dose and rate of increment of dose are not thought to play a role in the development of akathisia

(D) The symptoms of this condition are usually observed hours after administration of the causative drug
(E) The DSM IV research criteria for neuroleptic induced akathisia can be useful in the diagnosis of akathisia caused by other drugs

2. Drug induced parkinsonism (DIP):

(A) Signs of DIP take several months to become evident

(B) In DIP tremor and rigidity are the first clinical signs to emerge

(C) Dopamine receptor occupancy of up to $70 \%$ will cause DIP

(D) Atypical neuroleptics are less likely to cause DIP than drugs like haloperidol

(E) DIP is recognised in less than $20 \%$ of patients taking neuroleptics

\section{Neuroleptic malignant syndrome (NMS):}

(A) NMS can present clinically as a delirium

(B) NMS can cause renal failure

(C) Measurement of creatinine phosphokinase (CPK) levels are necessary if NMS is suspected

(D) Any psychoactive medication can give rise to NMS

(E) If NMS is suspected, anticholinergic medication should immediately be administered

\section{In serotonin toxicity:}

(A) Use of a serotonergic agent is necessary to make the diagnosis

(B) Only patients demonstrating neuro-excitatory, autonomic and neuromuscular features can be diagnosed with this condition

(C) Patients with palliative care needs may already have elevated serotonin levels

(D) Combinations of serotonergic drugs acting by different mechanisms are generally safe

(E) Initial treatment includes immediate discontinuation of serotonergic medication

Competing interests: None.

\section{REFERENCES}

1. Harris D. Delirium. Postgrad Med J 2007;83:525-8.

2. Centeno C, Sanz A, Bruera E. Delirium in advanced cancer patients. Palliat Med 2004;18:184-94.

3. Del Fabbro E, Dalal S, Bruera E. Symptom control in palliative care-part III: dyspnea and delirium. J Palliat Med 2006;9:422-36.

4. Lawlor PG, Gagnon B, Mancini IL, et al. Occurrence, causes, and outcome of delirium in patients with advanced cancer: a prospective study. Arch Intern Med 2000;160:786-94.

5. Moore AR, O'Keeffe ST. Drug-induced cognitive impairment in the elderly. Drugs Aging 1999;15:15-28.

6. Alagiakrishnan $\mathbf{K}$, Wiens CA. An approach to drug induced delirium in the elderly. Postgrad Med J 2004;80:388-93.

7. White C, McCann M, Jackson N. First do no harm, terminal restlessness and delirium. J Palliat Med 2007;10:345-51.

8. Karlsson I. Drugs that induce delirium. Dement Geriatr Cogn Disord 1999;10:412-5

9. Koponen HJ. Neurochemistry and delirium. Dement Geriatr Cogn Disord 1999;10:339-41.

10. Lipowski ZJ. Delirium, acute confusional state. Oxford: Oxford University Press, 1990

11. Mena MA, de Yebenes JG. Drug-induced parkinsonism. Expert Opin Drug Saf 2006:5:759-71.

12. Caligiuri MP, Lacro JP, Jeste DV. Incidence and predictors of drug-induced parkinsonism in older psychiatric patients treated with very low doses of neuroleptics. J Clin Psychopharmacol 1999;19:322-8.

13. Caligiuri MR, Jeste DV, Lacro JP. Antipsychotic-induced movement disorders in the elderly: epidemiology and treatment recommendations. Drugs Aging 2000;17:363-84.

14. Wenning GK, Kiechl S, Seppi K, et al. Prevalence of movement disorders in men and women aged 50-89 years (Bruneck study cohort): a population-based study. Lancet Neurol 2005:4:815-20. 
15. Barbosa MT, Caramelli P, Maia DP, et al. Parkinsonism and Parkinson's disease in the elderly: a community-based survey in Brazil (the Bambui study). Mov Disord 2006;21:800-8.

16. Hirose G. Drug induced parkinsonism: a review. J Neurol 2006;253(Suppl III):iii22-4.

17. Kuzuhara S. [Drug-induced parkinsonism]. Nippon Rinsho 1997;55:112-7.

18. White C, McPherson A, McCann MA, et al. Prolonged extra-pyramidal side effects after discontinuation of haloperidol as an antiemetic. Palliat Med 2006:20:215-6.

19. Ball R. Drug-induced akathisia: a review. J R Soc Med 1985;78:748-52

20. Hansen L, Wilkinson DG. Drug induced akathisia, suicidal ideation and its treatment in the elderly. Int J Geriatr Psychiatry 2001;16:231-3.

21. Tsuji Y, Miyama S, Uemura $Y$, et al. [Three cases of drug-induced akathisia due to antiemetics during cancer palliative care]. Gan To Kagaku Ryoho 2006:33:267-9.

22. Nelson DE. Akathisia_a brief review. Scott Med J 2001:46:133-4

23. Akagi H, Kumar TM. Lesson of the week: Akathisia: overlooked at a cost. BMJ 2002:324:1506-7.

24. Sachdev PS. Neuroleptic-induced movement disorders: an overview. Psychiatr Clin North Am 2005;28:255-74.

25. White C, Jackson N. Acute akathisia in palliative care. Eur J Palliat Care 2005:12:5-7.

26. Barnes TR. A rating scale for drug-induced akathisia. Br J Psychiatry 1989;154:672-6

27. Rathbone J, Soares-Weiser K. Anticholinergics for neuroleptic-induced acute akathisia. Cochrane Database Syst Rev 2006(4):CD003727.

28. Miller $\mathbf{C H}$, Hummer M, Oberbauer $\mathrm{H}$, et al. Risk factors for the development of neuroleptic induced akathisia. Eur Neuropsychopharmacol 1997:7:51-5.

29. Twycross R, Wilcock A, Charlesworth S, et al. Palliative care formulary, 2nd ed. Radcliffe Medical Press, 2003.

30. Marsden CD, Jenner P. The pathophysiology of extrapyramidal side-effects of neuroleptic drugs. Psychol Med 1980;10:55-72.

31. Girishchandra BG, Johnson L, Cresp RM, et al. Mirtazapine-induced akathisia Med J Aust 2002;176:242.

32. Sachdev P. A rating scale for acute drug-induced akathisia: development, reliability, and validity. Biol Psychiatry 1994:35:263-71.

33. Berardi D, Giannelli A, Barnes TR. Clinical correlates of akathisia in acute psychiatric inpatients. Int Clin Psychopharmacol 2000;15:215-9.

34. Kendell RE, Zealley AK. Companion to psychiatric studies, 5th ed. Churchill Livingstone, 1994.

35. Hansen L. A critical review of akathisia, and its possible association with suicidal behaviour. Hum Psychopharmacol 2001;16:495-505.

36. Jones M, Bennett J, Gray R, et al. Pharmacological management of akathisia in combination with psychological interventions by a mental health nurse consultant. J Psychiatr Ment Health Nurs 2006;13:26-32.

37. Sadock BJ, Sadock VA, eds. Kaplan and Sadock's synopsis of psychiatry, 9th ed Lippincott Williams and Wilkins, 2003.

38. Sachdev P. The epidemiology of drug-induced akathisia: part I. Acute akathisia Schizophr Bull 1995;21:431-49.

39. Twycross RWA, Charlesworth S, Dickman A. Palliative care formulary, 2nd ed Radcliffe Medical Press, 2003

40. Ener RA, Meglathery SB, Van Decker WA et al. Serotonin syndrome and other serotonergic disorders. Pain Med 2003;4:63-74.

41. Gillman PK. A review of serotonin toxicity data: implications for the mechanisms of antidepressant drug action. Biol Psychiatry 2006;59:1046-51.

42. Christensen RC. Identifying serotonin syndrome in the emergency department Am J Emerg Med 2005;23:406-8.

43. Mackay FJ, Dunn NR, Mann RD. Antidepressants and the serotonin syndrome in general practice. Br J Gen Pract 1999;49:871-4.

44. Bowdle TA. Adverse effects of opioid agonists and agonist-antagonists in anaesthesia. Drug Saf 1998;19:173-89.

45. Anderson T, Watson MS, Marr K. Serotonin syndrome: a hidden danger in palliative care. Eur J Palliat Care 2005:12:97-100.

46. Graudins A, Stearman A, Chan B. Treatment of the serotonin syndrome with cyproheptadine. J Emerg Med 1998;16:615-9.

47. Boyer EW, Shannon M. The serotonin syndrome. N Engl J Med 2005;352:1112-20.

48. Bijl D. The serotonin syndrome. Neth J Med 2004;62:309-13.

49. Gillman PK. Monoamine oxidase inhibitors, opioid analgesics and serotonin toxicity. Br J Anaesth 2005;95:434-41.

50. Birmes $\mathbf{P}$, Coppin D, Schmitt L, et al. Serotonin syndrome: a brief review. CMAJ 2003:168:1439-42.

51. Sternbach H. The serotonin syndrome. Am J Psychiatry 1991;148:705-13

52. Radomski JW, Dursun SM, Reveley MA, et al. An exploratory approach to the serotonin syndrome: an update of clinical phenomenology and revised diagnostic criteria. Med Hypotheses 2000;55:218-24.

53. Mason PJ, Morris VA, Balcezak TJ. Serotonin syndrome. Presentation of 2 cases and review of the literature. Medicine (Baltimore) 2000:79:201-9.

54. Mills KC. Serotonin syndrome. A clinical update. Crit Care Clin 1997;13:763-83.
55. Dunkley EJ, Isbister GK, Sibbritt D, et al. The Hunter Serotonin Toxicity Criteria: simple and accurate diagnostic decision rules for serotonin toxicity. $0 \mathrm{~J}$ Med 2003;96:635-42.

56. Amsterdam JD, Garcia-Espana F, Rosenzweig M. Clomipramine augmentation in treatment-resistant depression. Depress Anxiety 1997:5:84-90.

57. Turkel SB, Nadala JG, Wincor MZ. Possible serotonin syndrome in association with 5-HT(3) antagonist agents. Psychosomatics 2001:42:258-60.

58. Fisher AA, Davis MW. Serotonin syndrome caused by selective serotonin reuptakeinhibitors-metoclopramide interaction. Ann Pharmacother 2002;36:67-71.

59. Karki SD, Masood GR. Combination risperidone and SSRI-induced serotonin syndrome. Ann Pharmacother 2003;37:388-91.

60. Supe S, Matijevic V, Kondic L, et al. Series of seizures as a sign of development of recurrent malignant neuroleptic syndrome - a case report. Psychiatr Danub 2006;18(1-2):97-101

61. Norris B, Angeles V, Eisenstein R, et al. Neuroleptic malignant syndrome with delayed onset of fever following risperidone administration. Ann Pharmacother 2006:40:2260-4.

62. Norgard NB, Stark JE. Olanzapine-associated neuroleptic malignant syndrome. Pharmacotherapy 2006;26:1180-2.

63. Knight ME, Roberts RJ. Phenothiazine and butyrophenone intoxication in children Pediatr Clin North Am 1986:33:299-309.

64. Kawanishi C, Onishi H, Kato D, et al. Neuroleptic malignant syndrome in cancer treatment. Palliat Support Care 2005:3:51-3.

65. Morita T, Shishido H, Tei Y, et al. Neuroleptic malignant syndrome after haloperidol and fentanyl infusion in a patient with cancer with severe mineral imbalance. J Palliat Med 2004:7:861-4.

66. Normann C, Brandt C, Berger M, et al. Delirium and persistent dyskinesia induced by a lithium-neuroleptic interaction. Pharmacopsychiatry 1998;31:201-4.

67. Nachreiner R, Balledux J, Zieger $M$, et al. Neuroleptic malignant syndrome associated with metoclopramide in a burn patient. J Burn Care Res 2006;27:237-41.

68. Krahenbuhl S, Raisin J, Herren T. [Malignant neuroleptic syndrome under metoclopramide and neuroleptics in anuria]. Schweiz Med Wochenschr 1993; 123:1359-62.

69. Bakri YN, Khan R, Subhi J, et al. Neuroleptic malignant syndrome associated with metoclopramide antiemetic therapy. Gynecol Oncol 1992;44:189-90.

70. Le Couteur DG, Kay T. Delayed neuroleptic malignant syndrome following cessation of prolonged therapy with metoclopramide. Aust N Z J Med 1995:25:261.

71. Spivak B, Gonen N, Mester R, et al. Neuroleptic malignant syndrome associated with abrupt withdrawal of anticholinergic agents. Int Clin Psychopharmacol 1996;11:207-9.

72. Tanii H, Fujita K, Okazaki Y. Neuroleptic malignant syndrome related to a switch to perospirone and anticholinergic withdrawal. Am J Psychiatry 2006;163:547-8.

73. Hamada Y, Miyamoto K, Inatsugi $Y$, et al. [A case of Parkinson's disease with neuroleptic malignant syndrome induced by paroxetine]. Rinsho Shinkeigaku 2006:46:575-8

74. Sanai T, Matsui R, Hirano T, et al. Successful treatment of six patients with neuroleptic malignant syndrome associated with myoglobulinemic acute renal failure. Ren Fail 2006:28:51-5.

75. Rodriguez OP, Dowell MS. A case report of neuroleptic malignant syndrome withou fever in a patient given aripiprazole. J Okla State Med Assoc 2006;99:435-8.

76. Lu TC, Chu PL, Wu CS, et al. Neuroleptic malignant syndrome after the use of venlafaxine in a patient with generalized anxiety disorder. J Formos Med Assoc 2006:105:90-3.

77. Kasantikul D, Kanchanatawan B. Neuroleptic malignant syndrome: a review and report of six cases. J Med Assoc Thai 2006;89:2155-60.

78. Hall KL, Taylor WH, Ware MR. Neuroleptic malignant syndrome due to olanzapine. Psychopharmacol Bull 2001;35:49-54.

79. Hashimoto F, Sherman CB, Jeffery WH. Neuroleptic malignant syndrome and dopaminergic blockade. Arch Intern Med 1984:144:629-30.

80. Bond WS. Detection and management of the neuroleptic malignant syndrome. Clin Pharm 1984;3:302-7.

81. Rampertaap MP. Neuroleptic malignant syndrome. South Med J 1986;79:331-6

82. Gurrera R. Strategies for patients who are suspected of having acute neuroleptic malignant syndrome (NMS). 2003. http://www.mhc.com/Algorithms/Schizophrenia/ nms.htm

\section{ANSWERS}

1. $\quad(A) T(B) T(C) F(D) F(E) T$

2. (A) $F(B) F(C) F(D) T(E) F$

3. (A) $T$ (B) $T$ (C) $T$ (D) $F(E) F$

4. (A) $T$ (B) $F(C) T$ (D) $F(E) T$ 